\title{
Forecast of strong ground motion field near the fault for earthquake disaster reduction in urban areas
}

\author{
L. Haiming ${ }^{1,2}$, T. Xiaxin ${ }^{1}$, S. Xiaodan ${ }^{1}$ \& L. Ping ${ }^{1}$ \\ ${ }^{1}$ Harbin Institute of Technology, Harbin, China \\ ${ }^{2}$ Chongqing Communications Research \& Design Institute, \\ Chongqing, China
}

\begin{abstract}
Earthquake disasters are caused mainly from the damage and collapse of engineering structures, and the latter is mainly made by strong ground motion during the event. As city areas and scales of engineering structures are getting larger and larger in recent years, more than ever before, the forecast of strong ground motion field is emphasized. From a case study at Lanzhou city of China, a new developed approach is introduced in this paper. A hybrid source model that combines Asperity model with a $\mathrm{K}$ squire model is adopted. The high frequency motion is synthesized by random procedure and low frequency motion is calculated by a simplified numerical Green Function procedure, the two are combined in time domain after high and low pass filtered separately. Finally, the application of the result in the disaster reduction of the city is suggested.
\end{abstract}

Keywords: forecast, ground motion field, hybrid source model, random synthesis, numerical green function.

\section{Introduction}

In the development of modern cities, more and more large horizontal dimension structures, such as long span structures, fly-over crossings and buried pipelines have been built up in urban areas. Damage of those structures in an earthquake will cause large losses to the city. Thus, disaster risk assessments and reductions for cities, especially for those located near or above active faults, are emphasized in earthquake engineering field. Engineering countermeasures for the risk must 
be adopted, based on the forecast of strong ground motion field that have been difficult up to now. In this paper, a case study for earthquakes with a magnitude 6.5 in Lanzhou city of China is presented for illustration of the approach developed by the authors and their co-workers. A hybrid source model is adopted that combines Asperity model and the $\mathrm{K}$ square model to describe the dislocation distribution on the fault plan and the rupture process. The ground motion in high frequency range $(f>1 \mathrm{~Hz})$ is synthesized by a random method in which dynamic corner frequency is applied in each sub-source model. Two steps are carried out for the low frequency $(f<1 \mathrm{~Hz})$ motion. Firstly, the displacement field at the bottom of surface overlaid layer is calculated by analytical Green Function Method; then the ground motion at rock surface is calculated by $3 \mathrm{D}$ wave propagation finite element method with input from the first step. The two parts are finally superposed. The ground motion in basin area is further calculated by means of $1 \mathrm{D}$ equivalent linearization method. Peak ground acceleration map is finally presented.

\section{Hybrid source model}

The fault strikes $\mathrm{N} 60^{\circ} \mathrm{W}$ with a length of $115 \mathrm{~km}$, and its dip angle is $75^{\circ}$. It was estimated that the return period of an earthquake with a magnitude of 6.5 is about 500 years. From a set of scaling laws between moment magnitude and the parameters of fault rupture plane (Kanamori and Anderson [13]; Beresenv and Atkinson [9]; Tao and Wang [20]; Wang et al. [22]), the area is estimated as $136 \mathrm{~km}^{2}$, with a length $17 \mathrm{~km}$ and width of $8 \mathrm{~km}$, and average slip value $145.97 \mathrm{~cm}$. The whole plane is then divided into many sub-sources, and each of them is assigned a dislocation value while the total energy of all sub-sources is keeping to the same of the earthquake (Atkinson and Silva [5]; Beresenv and Atkinson [6]; Beresenv and Atkinson [7]; Beresenv and Atkinson [8]). The hybrid source model combines asperity model and $\mathrm{k}$ square model, which means the slip distribution on the finite fault is determined by the superimposition of the slip of long wave length calculated by asperity model and the slip of short wave length calculated by k square model (Tao and Wang [21]; Wang and Tao [20]). Asperity is for the part with much higher slip on the plane. There will be two asperities on the plane for an earthquake with magnitude 6.5. The parameters of the maximum asperity for the case study, are area $16.35 \mathrm{~km}^{2}$, length $8.71 \mathrm{~km}$ width $1.88 \mathrm{~km}$, center coordinates $3.24 \mathrm{~km}$ and $4.2 \mathrm{~km}$, and slip value $358.31 \mathrm{~cm}$, and those for the other are area $14.10 \mathrm{~km}^{2}$, length $3.75 \mathrm{~km}$, and slip $298.03 \mathrm{~cm}$. The parameters of the $\mathrm{k}$ square model are estimated as 0.0437 and 0.0692 for the expected values of $k_{c x}$ and $k_{c y}$ (Hanks and McGuire [12]). The uncertainties concerning with the above parameter values are furthermore taken into account by normal distributions with the standard deviations in the statistics. Total 30 source models are generated, and 4 of them are shown in figure 1, for examples.

The size of sub-source is taken as $1.0 \times 1.0 \mathrm{~km}^{2}$. The rupture process is governed by the focus position and the rupture velocity. The rupture velocity is 

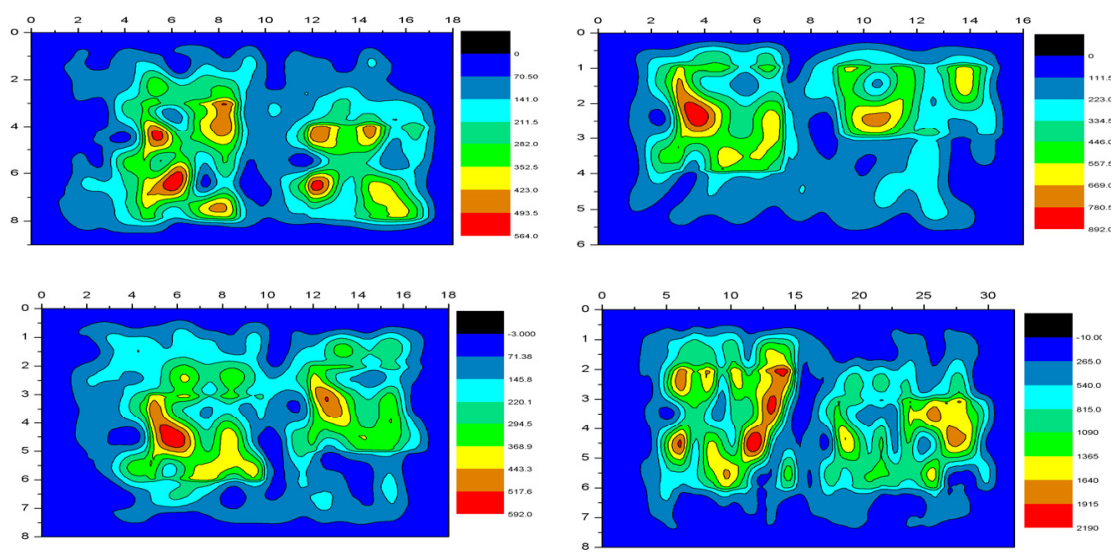

Figure 1: $\quad$ Four examples of the hybrid finite fault source models for the 6.5 earthquake on the fault.

taken as 0.85 of the shear wave velocity at the focus depth in the crust. The focus is randomly positioned outside of the asperity.

\section{High frequency ground motion synthesis}

The ground motion at high frequency range is synthesized by the random approach. Acceleration Fourier spectrum caused by each sub-source, as point source, can be inferred by the following equation (Atkinson and Boore [2]; Atkinson and Silva [5]).

$$
F A\left(M_{0}, f, R\right)=S\left(M_{0}, f\right) \cdot G(R) \cdot D(R, f) \cdot A(f) \cdot P(f)
$$

where $S\left(M_{0}, f\right)$ is source spectrum; $G(R)$ represents geometric attenuation; $D(R, f)$ stands for inelastic attenuation; $A(f)$ is surface amplification factor; $P(f)$ is a high pass filter. The acceleration time history at a given site can be obtained by summing those of all sub-sources with some time delays in time domain, as follows.

$$
a(t)=\sum_{i=1}^{N_{L}} \sum_{j}^{N_{W}} a_{i j}\left(t-t_{i j}\right)
$$

where $N_{L}$ and $N_{W}$ are numbers of sub-source along strike and down dip directions respectively; $t_{i j}$ is the time delay for the $i j$ th sub-source determined by the distance between sub-fault and hypocenter and the distance between the source and the site. In order to eliminate the effects of sub-source size on high frequency radiant energy, dynamic corner frequency (Motazedian and Atkinson [18]) is adopted herein. 
The parameters in equation (1) can be obtained from the regional study. For the study, shear wave velocity at the focus depth in the crust is $3.522 \mathrm{~km} / \mathrm{sec}$, stress drop at the focus area is 26 bar, quality factor Q value is $52 f^{1.09}$.

The ground motions at rock site are synthesized on 43254 points with spatial interval $200 \mathrm{~m} \times 200 \mathrm{~m}$.

\section{Low frequency ground motion calculation}

A simplified Numerical Green function is adopted to estimate ground motion in low frequency $(f<1 \mathrm{~Hz})$ range. The whole calculating model is divided into two parts, the deep part is simplified as homogenous zone and the source is in it, and the shallow part is inhomogeneous zone and dissected into finite elements, as shown in figure 2.
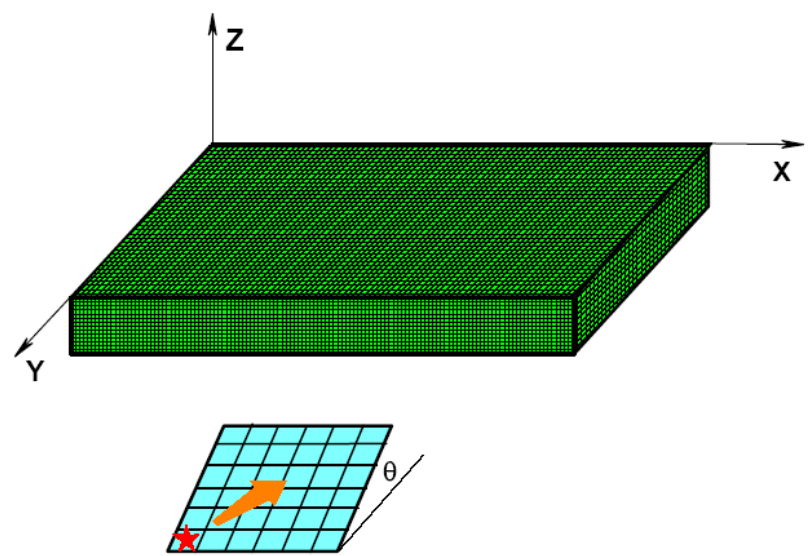

Figure 2: $\quad$ Sketch of the calculation model for low frequency motion.

Firstly, displacement time history for each node on the bottom of shallow part is calculated by the space-time convolution on the finite fault source in analytical way. 3-order Green function can be obtained from the superimposition of the corresponding 9 earthquake moment tensors, as shown in equation (3).

$$
F_{P} \times G_{n p}=\sum_{i=1}^{m} \sum_{j=1}^{n} F_{\varsigma} \times G_{\varsigma \eta}
$$

Afterwards, displacement time histories at all bottom nodes are input into the 3D finite element calculation. Secondly, displacement time histories at the ground surface nodes are calculated by the space-time decoupling explicit finite element approach with second-order local artificial transmitting boundary (Liao and Wong [15]; Liao [16]). The ground motions at rock site are calculated on the 43254 points. 


\section{Ground motion field and basin effect}

The motions at each point are superposed in time domain after low and high pass filtered. The ground motions at the 43254 points consist of the motion field. Figure 3 shows the peak ground acceleration map at rock site for Lanzhou city and its vicinity.

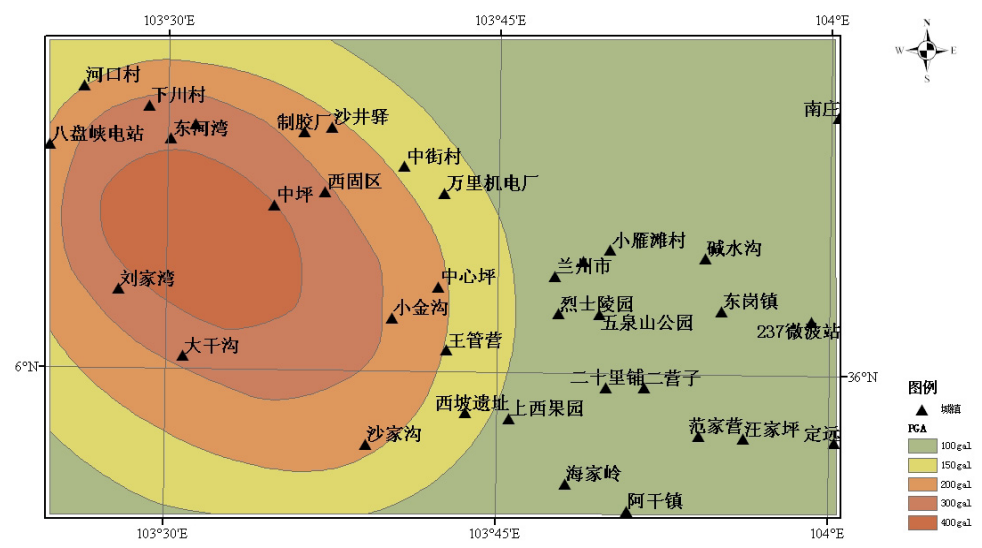

Figure 3: Peak ground acceleration zoning map at rock site in Lanzhou city and its vicinity caused by 6.5 earthquake.

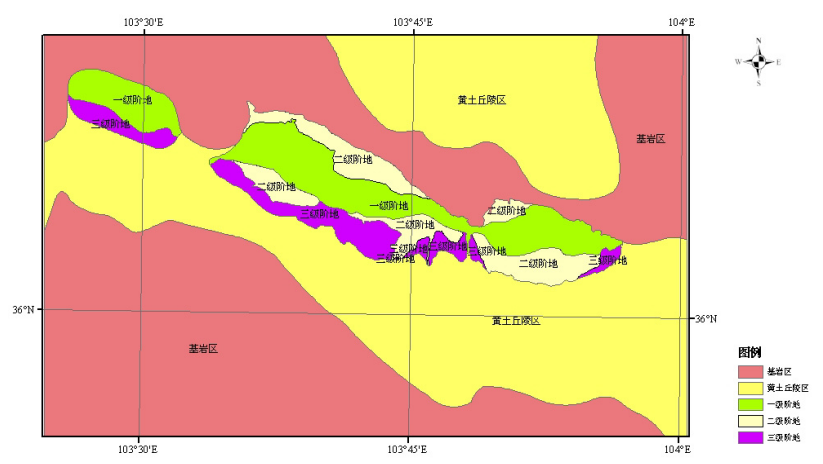

Figure 4: Site condition zoning map of Lanzhou city and its vicinity.

Most part of the Lanzhou city is covered by loess and Lanzhou basin covers a quite large area. Basically say, the seismic response of a basin can be obtained from a much more detail finite element calculation to describe the 3-D velocity structure of the basin. However, the minification of element size must result in the increase of computing amount. Thus, 1D equivalent linearization method is applied instead in the case study in the basin response analysis to describe the detail velocity structure as well as nonlinearity of soil layer. The zoning map of the site condition is shown in figure 4 . 
Transfer function of soil layers for each zone is calculated from borehole data. Ground motions beneath the basin, i.e. without surface amplification factor $A(f)$ in (1), are multiplied by the corresponding transfer function to get the ground motions in the basin area. The result peak ground acceleration zoning map is presented in figure 5 .

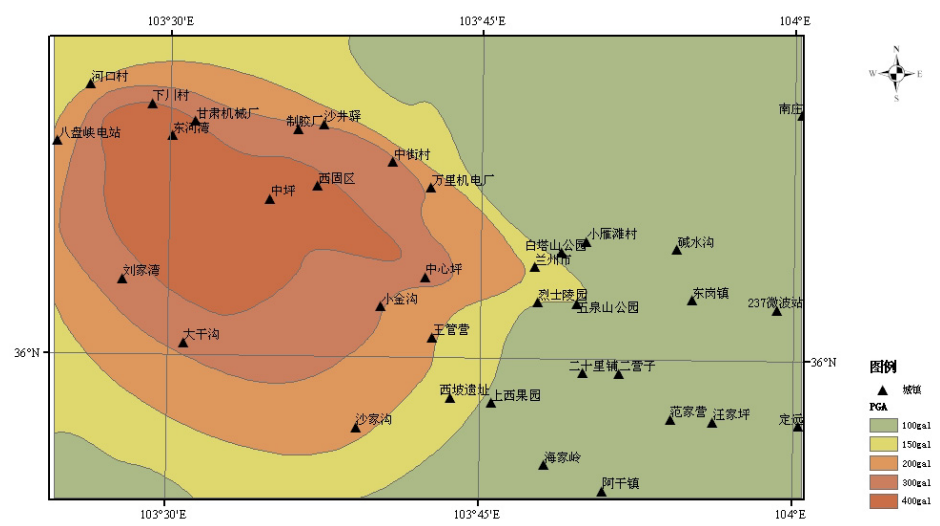

Figure 5: $\quad$ Peak ground acceleration zoning map of Lanzhou city and its vicinity caused by 6.5 earthquake at the fault segment conclusion.

Ground motion field at Lanzhou city of China is forecasted from an earthquake with magnitude 6.5 , as a case study. The result, peak ground acceleration map shows that the expected motion near the fault segment is much higher than 200 gal on that on the national seismic zoning map, those in most part of urban area are similar, from 150 gal to 300 gal, motion at the eastern part is less than 200 gal, even less than 100 gal for some places. This improvement is the result of detail exploration of earthquake active fault at the city. The potential source is narrowed down on the fault segment, and more parameters are adopted. And the amplification of soil layers in the basin is also taken into account from site condition zoning map.

\section{References}

[1] G. Atkinson. Earthquake source spectra in the Eastern North America [J]. Bulletin of the Seismological Society of America. 1993, 83(6): 1778-1798

[2] G. Atkinson and D. M. Boore. Stochastic point source modeling of ground motion in the Cascadia region [J]. Seismological Research Letter. 1997, 68(1): 74-85

[3] G. Atkinson and D. M. Boore. Evaluation of models for earthquake source spectra in eastern North America [J]. Bulletin of the Seismological Society of America. 1998, 88(4): 917-934 
[4] G. Atkinson and W. Silva. An empirical study of earthquake source spectra for California earthquakes [J]. Bulletin of the Seismological Society of America. 1997, 87(1): 97-113

[5] G. Atkinson and W. Silva. Stochastic modeling of California ground motions [J]. Bulletin of the Seismological Society of America. 2000, 90(2): 255-274

[6] I. A. Beresenv and G. Atkinson. Modeling finite-fault radiation from the $\omega^{\mathrm{n}}$ spectrum [J]. Bulletin of the Seismological Society of America. 1997, 87(1): $67-84$

[7] I. A. Beresenv and G. Atkinson. Stochastic finite-fault modeling of ground motions from the 1994 Northridge, California, earthquake, I. Validation on rock sites [J]. Bulletin of the Seismological Society of America. 1998, 88(6): 1392-1401

[8] I. A. Beresenv and G. Atkinson. Generic finite-fault model for groundmotion prediction in Eastern North America [J]. Bulletin of the Seismological Society of America. 1999, 89(3): 608-625

[9] I. A. Beresenv and G. Atkinson. Source parameters of earthquakes in eastern and western North America based on finite-fault modelling [J]. Bulletin of the Seismological Society of America. 2002, 92(2): 695-710

[10] J. G. Boatwright and G. L. Choy. Acceleration source spectra anticipated for large earthquakes in northeastern North America [J]. Bulletin of the Seismological Society of America. 1992, 82(2): 660-682

[11] T. C. Hanks. b values and $\omega^{2}$ seismic source models: implications for tectonic stress variation along active crustal fault zones and the estimation of high-frequency strong ground motion [J]. Journal of Geophysical Research. 1979, 84(5): 2235-2242

[12] T. C. Hanks and R. K. McGuire. The character of high-frequency strong ground motion [J]. Bulletin of the Seismological Society of America. 1981, 71(6): 2071-2095

[13] H. Kanamori and D. L. Anderson. Theoretical basis of some empirical relations in seismology [J]. Bulletin of the Seismological Society of America. 1975, 65(5): 1073-1095

[14] T. Khosrow, K. T. Shabestari and F. Yamazaki. Near-fault spatial variation in strong ground motion due to rupture directivity and hanging wall effects from the Chi-Chi, Taiwan earthquake [J]. Earthquake Engineering and Structure Dynamic. 2003, 32(14): 2197-2219

[15] Z.P. Liao, H. L. Wong. A Transmitting Boundary for the Numerical Simulation of Elastic Wave Propagation [J]. Soil Dynamics and Earthquake Engineering. 1984, 3(4):174-183

[16] Z.P. Liao. Extrapolation Non-reflecting Boundary Conditions[J]. Wave Motion. 1996, 24:117-138

[17] B. Mohammadioum and L. Serva. Stress drop, slip type, earthquake magnitude, and seismic hazard [J]. Bulletin of the Seismological Society of America. 2001, 91(4):694-707 
[18] D. Motazedian and G. M. Atkinson. Stochastic finite-fault modeling based on a dynamic corner frequency [J]. Bulletin of the Seismological Society of America. 2005, 95(3): 995-1010

[19] X. X. Tao and J. G. Anderson. Near field strong ground motion simulation [C]. Proceeding of International Conference on Advances and New Challenges in Earthquake Engineering Research, Harbin. 2002

[20] X. X. Tao and G. X. Wang. Rupture directivity and hanging wall effect in near field strong ground motion simulation $[\mathrm{J}]$. ACTA Seismologica Sinica, 2003, 16(2): 205-212

[21] X. X. Tao and H. Y. Wang. A random source model for near filed strong ground motion prediction [C]. Proceeding of the 13th World Conference on Earthquake Engineering, Vancouver, Canada, 2004

[22] H. Y. Wang, X. X. Tao and J. Li. Global source parameters of finite fault model for strong ground motion predictions [C]. Proceeding of the 13th World Conference on Earthquake Engineering, Vancouver, Canada, 2004

[23] H. Y. Wang and X. X. Tao. Relationships between moment magnitude and fault parameters: theoretical and semi-empirical relations $[\mathrm{J}]$. Earthquake Engineering and Engineering Vibration. 2003, 2(2): 201-211 